\title{
Prostacyclin Produced by the Pregnant Uterus in the Dog May Act as a Circulating Vasodepressor Substance
}

\author{
John G. Gerber, N. Ann Payne, Robert C. Murphy, and Alan S. Nies, Division \\ of Clinical Pharmacology and Toxicology, University of Colorado Health \\ Sciences Center, Denver, Colorado 80262
}

\begin{abstract}
A B S T RACT Uterine production of $\mathrm{PGI}_{2}$ (prostacyclin) was quantitated in late pregnant dogs to evaluate if $\mathrm{PGI}_{2}$ could act as a circulating vasodepressor substance in pregnancy. In five anesthetized, laparotomized dogs, the uterine venous plasma concentration of 6-keto $\mathrm{PGF}_{1 \alpha}$ (the in vitro hydrolysis product of $\mathrm{PGI}_{2}$ ) was $6.7 \pm 1.9 \mathrm{ng} / \mathrm{ml}$ and the arterial plasma concentration was $2.6 \pm 0.8 \mathrm{ng} / \mathrm{ml}$. In four nonpregnant female dogs the arterial plasma concentration of 6-keto $\mathrm{PGF}_{1 \alpha}$ was consistently below $0.2 \mathrm{ng} / \mathrm{ml}$. In eight pregnant dogs we also evaluated the ability of the pregnant uterus to inactivate $\mathrm{PGI}_{2}$ by comparing the hypotensive response to increasing doses of $\mathrm{PGI}_{2}$ infused into the uterine artery to the hypotensive response to increasing doses of $\mathrm{PGI}_{2}$ infused into the inferior vena cava. In addition, the effect of $\mathrm{PGI}_{2}$ infused into the uterine artery on uterine blood flow and intraamniotic fluid pressure was evaluated. The dose-response curves of intrauterine and intravenous $\mathrm{PGI}_{2}$ in causing systemic hypotension were identical suggesting that the pregnant uterus does not inactivate infused $\mathbf{P G I}_{2}$. Intrauterine $\mathbf{P G I}_{2}$ had no consistent effect on uterine hemodynamics although it did increase intraamniotic fluid pressure significantly. These data demonstrate that the pregnant uterus has the capacity to produce large quantities of $\mathrm{PGI}_{2}$ which is not inactivated in the uterus and therefore can appear in the arterial blood to exert a systemic vasodepressor effect.
\end{abstract}

\section{INTRODUCTION}

Despite salt and water retention and a large increase in cardiac output, pregnancy is associated with a slight decrease in mean arterial pressure (1). This decrease in arterial pressure is secondary to an even larger decrease

Dr. Gerber is an Established Investigator of the American Heart Association.

Received for publication 21 July 1980 and in revised form 10 October 1980. in total peripheral vascular resistance. The mediator of the decreased peripheral vascular resistance is not known, but prostaglandins have been implicated to play a role in this effect. We have recently reported that the late pregnant uterus in the dog is capable of synthesizing large amounts of prostaglandin $\mathrm{E}_{2}\left(\mathrm{PGE}_{2}\right)^{1}$ which is a potent vasodepressor agent (2). Even though the uterine venous levels of $\mathrm{PGE}_{2}$ were in the nanogram per milliliter range, the arterial $\mathrm{PGE}_{2}$ levels were too low to detect. Because of the large capacity of the lungs to metabolize $\mathrm{PGE}_{2}$, it is unlikely that $\mathrm{PGE}_{2}$ could have a systemic role in controlling blood pressure from a distant organ like the pregnant uterus. However, prostacyclin $\left(\mathrm{PGI}_{2}\right)$, unlike $\mathrm{PGE}_{2}$, travels through the lung intact making it a good candidate for a circulating depressor hormone (3).

The present study was undertaken to evaluate the capacity of $\mathrm{PGI}_{2}$ production by the pregnant uterus in the dog and to study the ability of the pregnant uterus to inactivate $\mathrm{PGI}_{2}$.

\section{METHODS}

(A). Eight mongrel dogs, weighing between $16-28 \mathrm{~kg}$, in late pregnancy but before labor, were anesthetized using pentobarbital, $30 \mathrm{mg} / \mathrm{kg}$, and placed on a positive pressure respirator pump. One femoral artery and one femoral vein were catheterized for blood pressure monitoring, and drug and fluid administration, respectively. Through a low abdominal incision, the pregnant uterus was exposed and one of the uterine veins was cannulated from a smaller venous branch. The right main uterine artery was identified and a noncannulating electromagnetic flow probe was placed around the artery to measure continuously uterine blood flow via a flowmeter (Statham Instruments, Inc., Oxnard, Calif.). The uterine artery was then punctured with a curved 27-gauge needle connected to a polyethylene tube for the intrauterine infusion of $\mathrm{PGI}_{2}$. Amniotic fluid pressure was continuously monitored on the right

\footnotetext{
${ }^{1}$ Abbreviations used in this paper: 6-keto $\mathrm{PGF}_{1 \mathrm{\alpha}}, 6$-keto prostaglandin $\mathrm{F}_{1 \alpha} ; \mathrm{PGE}_{2}$, prostaglandin $\mathrm{E}_{2} ; \mathrm{PGI}_{2}$, prostacyclin.
} 
side through a floating catheter in the amniotic sac attached to a pressure transducer. After the surgery, we allowed $\sim 45 \mathrm{~min}$ for stabilization.

In five of the animals $30 \mathrm{ml}$ of uterine venous and $30 \mathrm{ml}$ of arterial blood were withdrawn into plastic syringes containing $0.1 \mathrm{vol}$ of $3.8 \%$ sodium citrate and $1 \mathrm{mM}$ indomethacin for the analysis of the plasma for 6-keto $\mathrm{PGF}_{1 \alpha}$, the acid hydrolysis product of $\mathrm{PGI}_{2}$.

To evaluate the hemodynamic and uterine contractile effects of $\mathrm{PGI}_{2}$, plus the ability of the pregnant uterus to inactivate $\mathrm{PGI}_{2}$, we infused $\mathrm{PGI}_{2}$ first into the uterine artery and then into the inferior vena cava at doses of 3,10 , 30 , and $100 \mathrm{ng} / \mathrm{kg}$ per min. Mean arterial pressure, uterine blood flow, and intraamniotic fluid pressure were continuously monitored. Between doses of $\mathrm{PGI}_{2}$, a 30 -min stabilization period was introduced to allow all the hemodynamic parameters to return to base line.

$(B)$. Four nonpregnant female dogs weighing between $18-25 \mathrm{~kg}$ were anesthetized with $30 \mathrm{mg} / \mathrm{kg}$ pentobarbital i.v. and placed on a positive pressure respirator pump. The femoral artery and vein were catheterized as with the pregnant dogs. Through a midabdominal incision the nonpregnant uterus was identified and manipulated to a similar degree as with the eight pregnant animals in section $\mathrm{A}$. The incision was then closed and the animals were allowed to stabilize for $45 \mathrm{~min}$. When the animals were hemodynamically stable, $30 \mathrm{ml}$ of arterial blood was collected in plastic syringes containing 0.1 vol of $3.8 \%$ sodium citrate and $1 \mathrm{mM}$ indomethacin for the subsequent analysis of the plasma for the measurement of 6-keto PGF $1 \alpha$.

(C). Analysis of 6-keto PGF $F_{1 \alpha}$ concentration in the plasma. $500 \mathrm{ng}$ of tetradeutero 6-keto $\mathrm{PGF}_{1 \alpha}$ (a gift of Dr. John Pike, Upjohn Co., Kalamazoo, Mich.) was added to the plasma as the internal standard and 100,000 cpm of tritiated 6-keto PGF (New England Nuclear, Boston, Mass.) was added to the plasma to facilitate the isolation and purification of the prostaglandin. The prostaglandin was extracted into $3 \mathrm{vol}$ of ethyl acetate after acidification of the plasma to $\mathrm{pH} 3$ with $1 \mathrm{~N}$ $\mathrm{HCl}$. The extract was initially purified over an open silicic acid column and eluted with chloroform (96)/methanol (4)/ acetic acid (0.1) (vol/vol/vol). The extract was further purified and separated by using two high pressure liquid chromatography steps using the fatty acid column and $\mu$ Porasil columns (Waters Associates, Inc., Milford, Mass.) sequentially. The purified 6-keto $\mathrm{PGF}_{1 \alpha}$ was then derivatized to the methoxime, methyl ester, trimethylsilyl derivative.

The derivatized prostaglandin was analyzed by gas chromatography-mass spectrometer under electron impact conditions $(70 \mathrm{eV})$. The gas chromatography was performed with a silanized glass column containing 3\% OV 101 on Gas-Chrom 120/ 140 (Applied Science Labs., Inc., State College, Pa.) at an oven temperature of $240-250^{\circ} \mathrm{C}$. The prostaglandin was analyzed on a Finnigan 3200 quadrupole mass spectrometer using selected ion monitoring under control of a Finnigan 6100 data system (Finnigan Corp., Sunnyvale, Calif.). The ion pairs (mass/energy) 598 and 602 were monitored for estimating the ratio of $\mathrm{D}_{0} / \mathrm{D}_{4}$ 6-keto prostaglandin $\mathrm{F}_{1 \alpha}\left(6\right.$-keto $\left.\mathrm{PGF}_{1 \alpha}\right)$ in the biologic samples. The principles and details of these procedures have been recently described by Green et al. (4). The detection limit for estimating 6-keto $\mathrm{PGF}_{1 \alpha}$ plasma concentrations using $15 \mathrm{ml}$ of plasma was $200 \mathrm{pg} / \mathrm{ml}$.

This method measures both $\mathrm{PGI}_{2}$, which hydrolyzes to 6keto $\mathrm{PGF}_{1 \alpha}$ during the work-up of the plasma, as well as preformed 6-keto $\mathrm{PGF}_{1 \alpha}$, which is in plasma at the time of sampling. In vivo, $\mathrm{PGI}_{2}$ is thought to be metabolized predominately to 15 -keto $\mathrm{PGI}_{2}$ and then to 6,15 diketo $\mathrm{PGF}_{1 \alpha}$ and 6-keto $\mathrm{PGF}_{1 \alpha}$ is probably not a major in vivo product of $\mathrm{PGI}_{2}(5,6)$.
TABLE I

Arterial and Uterine Venous Concentrations of 6-keto PGF $F_{1 \alpha}$ in Pregnant and Nonpregnant Dogs

\begin{tabular}{|c|c|c|}
\hline \multicolumn{2}{|c|}{ Pregnant } & \multirow{2}{*}{$\frac{\text { Nonpregnant }}{\text { Arterial }}$} \\
\hline Arterial & Uterine vein & \\
\hline \multicolumn{3}{|c|}{$n g / m l$} \\
\hline 3.42 & 9.26 & $<0.2$ \\
\hline 1.46 & 1.77 & $<0.2$ \\
\hline 1.33 & 11.77 & $<0.2$ \\
\hline 1.28 & 2.74 & $<0.2$ \\
\hline 5.62 & 7.86 & \\
\hline $2.62 \pm 0.85$ & $6.68 \pm 1.92$ & \\
\hline
\end{tabular}

Measurement of 6-keto $\mathrm{PGF}_{1 \alpha}$ in plasma, therefore, most likely reflects primarily circulating $\mathrm{PGI}_{2}$.

Statistics. A paired Student's $t$ test was used to analyze the changes in uterine blood flow, uterine vascular resistance, intraamniotic fluid pressure, and mean arterial pressure secondary to intrauterine $\mathrm{PGI}_{2}$ infusion. An unpaired Student's $t$ test was used to compare the hypotensive effect of intrauterine $\mathrm{PGI}_{2}$ infusion to intravenous $\mathrm{PGI}_{2}$ infusion. A $P$ value of $<0.05$ was considered significant.

\section{RESULTS}

In the five pregnant dogs, the mean uterine vein and arterial plasma concentrations of 6-keto $\mathrm{PGF}_{1 \alpha}$ were $6.68 \pm 1.92$ and $2.62 \pm 0.85 \mathrm{ng} / \mathrm{ml}$, respectively. In the nonpregnant female dogs, the arterial plasma concentrations of 6-keto $\mathrm{PGF}_{1 \alpha}$ were below the detection limit of our assay in all four of the animals $(<200 \mathrm{pg} / \mathrm{ml})$ (Table I).

Infusion of increasing concentrations of $\mathrm{PGI}_{2}$ resulted in a progressive decrease in mean arterial pressure. There was no difference in the hypotensive response to $\mathrm{PGI}_{2}$ whether the prostaglandin was infused intravenously or into the pregnant uterus (Fig. 1). This suggests that very little if any of the $\mathrm{PGI}_{2}$ traveling through the uterus is metabolized to inactive compounds. Since $\mathrm{PGI}_{2}$ is not inactivated by the lungs, $\mathrm{PGI}_{2}$ produced by the pregnant uterus would be expected to travel to the systemic circulation intact. Our data showing high uterine venous as well as arterial plasma 6keto $\mathrm{PGF}_{1 \alpha}$ concentrations are consistent with the lack of the lung metabolism of $\mathrm{PGI}_{2}$. Although the metabolism of intrauterine-generated $\mathrm{PGI}_{2}$ may be different than the metabolism of infused $\mathrm{PGI}_{2}$, this difference has not been demonstrated for either $\mathrm{PGI}_{2}$ or other prostaglandins. Using the above infusion technique we have previously shown that the liver is the major organ to inactivate $\mathrm{PGI}_{2}(3)$.

The local hemodynamic effects of intrauterine infusion of $\mathrm{PGI}_{2}$ were variable. Neither uterine blood flow 


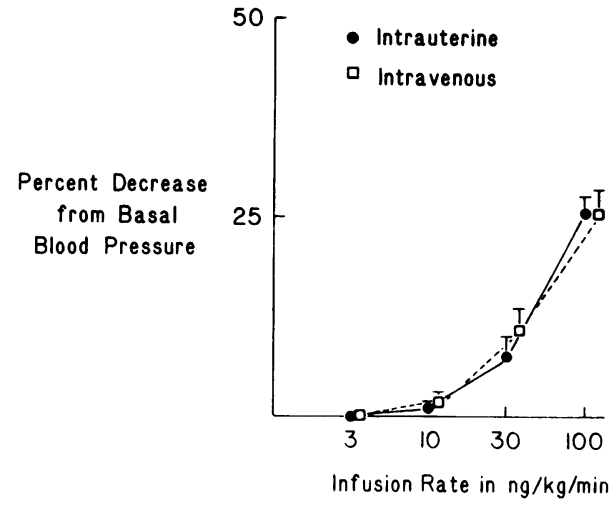

FIGURE 1 The systemic hypotensive effect of intrauterine and intravenous infusion of $\mathrm{PGI}_{2}$. The abscissa represents increasing infusion rate of $\mathrm{PGI}_{2}$ and the ordinate represents the percent decrease in mean arterial pressure from the control.

nor uterine vascular resistance were significantly altered when the intrauterine infusion of $\mathrm{PGI}_{2}$ reached a steady state. In all of the animals, however, we could observe a transient increase in uterine blood flow at the start of the $\mathrm{PGI}_{2}$ infusion, but by 3 min these changes were not significant. This is in contrast to the effects of $\mathrm{PGI}_{2}$ on other vascular beds where the increases in organ blood flows were maintained for the duration of the $\mathrm{PGI}_{2}$ infusion $(7,8)$. The hypotensive effect of the higher doses of $\mathrm{PGI}_{2}$ was maintained for the duration of the $\mathrm{PGI}_{2}$ infusion suggesting that the vascular resistance in organs other than the uterus remained below control levels.

The two highest doses of intrauterine $\mathrm{PGI}_{2}$ infusion significantly increased intraamniotic fluid pressure,

TABLE II

Hemodynamic Effects of Intrauterine PGI Infusion $_{2}$

\begin{tabular}{ccccc}
\hline & $\begin{array}{c}\text { Mean uterine } \\
\text { blood flow }\end{array}$ & $\begin{array}{c}\text { Uterine } \\
\text { resistance }\end{array}$ & $\begin{array}{c}\text { Intraamniotic } \\
\text { pressure }\end{array}$ & $\begin{array}{c}\text { Mean } \\
\text { arterial } \\
\text { pressure }\end{array}$ \\
\hline ng/kg/min & $m l / m i n$ & $m m ~ H g / m l / m i n$ & $m m H g$ & $m m H g$ \\
Control & $146 \pm 27$ & $1.03 \pm 0.24$ & $7.7 \pm 0.7$ & $112 \pm 4$ \\
3 & $153 \pm 27$ & $0.93 \pm 0.18$ & $7.8 \pm 0.8$ & $112 \pm 4$ \\
Control & $150 \pm 26$ & $1.00 \pm 0.23$ & $7.9 \pm 0.8$ & $113 \pm 5$ \\
10 & $150 \pm 25$ & $0.93 \pm 0.17$ & $8.6 \pm 1.0$ & $111 \pm 4$ \\
Control & $148 \pm 24$ & $1.00 \pm 0.14$ & $7.9 \pm 0.6$ & $112 \pm 4$ \\
30 & $155 \pm 28$ & $0.90 \pm 0.17$ & $9.2 \pm 0.9^{*}$ & $103 \pm 5^{*}$ \\
Control & $153 \pm 25$ & $0.96 \pm 0.17$ & $7.9 \pm 0.6$ & $116 \pm 5$ \\
100 & $103 \pm 25^{*}$ & $0.97 \pm 0.10$ & $12.7 \pm 2.1^{*}$ & $83 \pm 4^{*}$ \\
\hline
\end{tabular}

${ }^{*} P<0.05$ paired $t$ test. suggesting a contractile effect of the prostaglandin on the pregnant myometrium (Table II). Whether this was a direct effect of $\mathrm{PGI}_{2}$ or an indirect effect as a consequence of systemic hypotension was not elucidated. Since increased intrauterine pressure is associated with an increase in uterine vascular resistance (9), it is possible that the true vascular dilatory effect of $\mathrm{PGI}_{2}$ was camouflaged by the increase in uterine vascular resistance as a consequence of the increased intrauterine pressure. This dynamic relationship between uterine blood flow and intrauterine pressure was well demonstrated in one of the dogs, where the intrauterine infusion of $100 \mathrm{ng} / \mathrm{kg}$ per min of $\mathrm{PGI}_{2}$ caused a transient increase in blood flow followed by a marked decrease coincident with a large increase in intraamniotic fluid pressure (Fig. 2).

\section{DISCUSSION}

The role that prostaglandins play during pregnancy is unclear. Prostaglandins are thought to be important in maintaining a patent ductus in the fetus (10), in initiating labor (11), and maintaining some uterine myo-

\section{Mean Arterial Pressure $(\mathrm{mm} \mathrm{Hg})$}
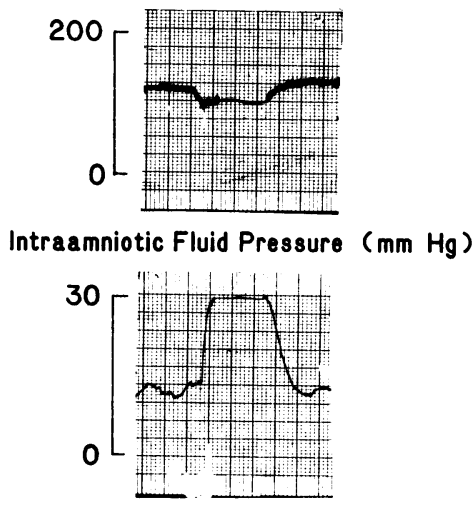

Uterine Blood Flow ( $\mathrm{ml} / \mathrm{min}$ )

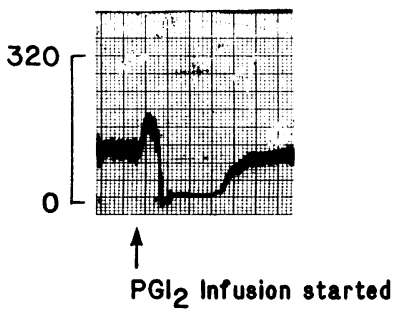

FIGURE 2 The effect of intrauterine $\mathrm{PGI}_{2}$ infusion ( $100 \mathrm{ng} / \mathrm{kg}$ per min) on mean arterial pressure, intraamniotic fluid pressure, and uterine blood flow in one of the dogs that had an excessive response to $\mathrm{PGI}_{2}$. The uterine blood flow shows a transient increase in flow followed by a sustained decrease concomitant with the large increase in intraamniotic fluid pressure. Each vertical line represents 2 min. 
metrial tone $(2,12)$. Another possible role of prostaglandins in pregnancy is maintaining a low peripheral vascular resistance. For a prostaglandin to fit the role of a systemic vasodilator in pregnancy, the following criteria need to be met. The pregnant uterus has to have the capacity to make the prostaglandin, and the prostaglandin has to escape inactivation by both the uterus and the lung to appear in the arterial blood to exert an effect. We have previously demonstrated that $\mathrm{PGE}_{2}$, a potent vasodilator, was produced by the pregnant uterus of the dog. Even though the mean uterine venous level of $\mathrm{PGE}_{2}$ was found to be $1.6 \mathrm{ng} / \mathrm{ml}$, the arterial level of $\mathrm{PGE}_{2}$ was consistently not detectable suggesting extensive pulmonary metabolism. Our present data demonstrate that $\mathrm{PGI}_{2}$, measured as the acid hydrolysis product of 6-keto $\mathrm{PGF}_{1 \alpha}$, is also produced in generous quantities by the pregnant uterus of the dog, but unlike $\mathrm{PGE}_{2}$, recirculates to appear in the arterial blood. In addition, when $\mathrm{PGI}_{2}$ was infused into the uterine artery, it proved to be as potent as vasodepressor agent as when it was infused intravenously, thus demonstrating that $\mathrm{PGI}_{2}$ escaped inactivation by the pregnant uterus.

Although we were measuring 6-keto $\mathrm{PGF}_{1 \alpha}$ concentration in the plasma which is a composite of both intact $\mathrm{PGI}_{2}$ (hydrolyzed to 6-keto $\mathrm{PGF}_{1 \alpha}$ ex vivo) and already present 6-keto $\mathrm{PGF}_{1 \alpha}$, the uterus does not synthesize 6-keto $\mathrm{PGF}_{1 \alpha}$ but produces $\mathrm{PGI}_{2}$, which is then nonenzymatically hydrolyzed to 6-keto $\mathrm{PGF}_{1 \alpha}$. Thus, the uterine venous minus arterial concentration of 6keto $\mathrm{PGF}_{1 \alpha}$ most likely represents net $\mathrm{PGI}_{2}$ synthesis. Since the half-life of $\mathrm{PGI}_{2}$ dissolved in blood is $3 \mathrm{~min}$ (13), and the lung does not metabolize $\mathrm{PGI}_{2}$, a significant portion of the uterine synthesized $\mathrm{PGI}_{2}$ could reach the arterial circulation unchanged. The reports that angiotensin II stimulation of $\mathrm{PGI}_{2}$ synthesis in the canine lung (14) and kidney (15) results in a platelet effect also strongly argues in favor of $\mathrm{PGI}_{2}$ being released intact from organs.

The hypothesis that $\mathrm{PGI}_{2}$ may be an important circulating vasodepressor hormone in pregnancy is attractive from several viewpoints. Pregnancy is associated with a decline in blood pressure and peripheral vascular resistance, the mechanism of which is unclear. Indeed the mean blood pressure in our anesthetized, pregnant dogs was significantly lower than in the four anesthetized, nonpregnant controls ( $112 \pm 4$ vs. $141 \pm 9$ $\mathrm{mm} \mathrm{Hg} ; P<0.05$, unpaired $t$ test). The possibility that circulating $\mathrm{PGI}_{2}$ is partially responsible for the decrease in peripheral vascular resistance in pregnancy gains substance from our data. In addition, pregnancy is associated with elevated plasma renin activity and vascular angiotensin resistance (16). This vascular insensitivity to angiotensin is analogous to that seen in Bartter's syndrome, where prostaglandin inhibition can ameliorate the vascular defects of the syndrome (17). Thus, it is conceivable that the high concentration of circulating $\mathrm{PGI}_{2}$ is responsible for both the elevated plasma renin activity as well as angiotensin insensitivity in pregnancy.

The actual amount of $\mathrm{PGI}_{2}$ secreted by the pregnant uterus in the unanesthetized, uninstrumented dog could be several fold less than in the anesthetized and laparotomized animal. Both the stress of anesthesia and laparotomy has been shown to increase prostaglandin production by the kidney (18). Nonetheless, in the four nonpregnant dogs that also underwent anesthesia and laparotomy the arterial plasma concentrations of 6-keto $\mathrm{PGF}_{1 \alpha}$ were below the sensitivity of our assay suggesting that indeed the capacity of the pregnant uterus to make $\mathrm{PGI}_{2}$ must be very high and that anesthesia, per se, cannot explain our results.

We can conclude from our data that $\mathrm{PGI}_{2}$, measured as 6-keto $\mathrm{PGF}_{1 \alpha}$, is produced by the pregnant uterus in the dog and that the arterial concentration of 6-keto $\mathrm{PGF}_{1 \alpha}$ in pregnant animals is elevated above that of the nonpregnant dogs. In addition, although the pregnant uterus makes $\mathrm{PGI}_{2}$, probably does not play any role in inactivating it. Thus, uterine $\mathrm{PGI}_{2}$ is a likely mediator to contribute to the lowered systemic vascular resistance in pregnancy.

\section{ACKNOWLEDGMENTS}

This work was supported by research grants GM-07063, HL21308, and GM-19897 from the National Institutes of Health.

\section{REFERENCES}

1. Lees, M. M., S. H. Taylor, F. B. Scott, and M. G. Kerr. 1967. A study of cardiac output at rest throughout pregnancy. J. Obstet. Gynaecol. Br. Commonw. 74: 319-328.

2. Gerber, J. G., R. A. Branch, W. C. Hubbard, and A. S Nies. 1978. Indomethacin is a placental vasodilator in the dog. The effect of prostaglandin inhibition.J. Clin. Invest. 62: $14-18$.

3. Gerkens, J. F., G. C. Friesinger, R. A. Branch, D. G. Shand, and J. G. Gerber. 1978. A comparison of the pulmonary, renal and hepatic extractions of $\mathrm{PGE}_{2}$ and $\mathrm{PGI}_{2}-\mathrm{PGI}_{2}$, a potential circulating hormone. Life Sci. 22: 1837-1842.

4. Gréen, K., M. Hamberg, B. Samuelsson, and J. C. Frölich. 1978. Extraction and chromatographic procedures for purification of prostaglandins, thromboxanes, prostacyclin and their metabolites. Adv. Prostaglandin Thromboxane Res. 5: 39-94.

5. McGuire, J. C., and F. F. Sun. 1978. Metabolism of prostacyclin:oxidation by rhesus monkey lung 15-hydroxyl prostaglandin dehydrogenase. Arch. Biochem. Biophys. 189: 92-96.

6. Sun, F. F., and B. M. Taylor. 1978. Metabolism of prostacyclin in rat. Biochemistry. 17: 4096-4101.

7. Gerber, J. G., A. S. Nies, G. C. Friesinger, J. F. Gerkens, R. A. Branch, and J. A. Oates. 1978. The effect of PGI on canine renal function and hemodynamics. Prostaglandins. 16: 519-528. 
8. Gerkens, J. F., J. G. Gerber, D. G. Shand, and R. A. Branch. 1978. Effect of $\mathrm{PGI}_{2}$ on canine gastric blood flow and acid secretion: a possible role in gastric physiology. Prostaglandins. 16: 815-823.

9. Novy, M. J., C. L. Thomas, and M. H. Lees. 1975. Uterine contractility and regional blood flow responses to oxytocin and prostaglandin $\mathrm{E}_{2}$ in pregnant rhesus monkeys. $\mathrm{Am}$. J. Obstet. Gynecol. 122: 419-433.

10. Heyman, M. A., and A. M. Rudolph. 1976. Effects of acetylsalicylic acid on the ductus arteriosus and circulation in fetal lambs in uterus. Circ. Res. 38: 418-422.

11. Wiqvist, N., M. Bygdeman, K. Gréen, and V. Lundstrom. 1975. Endogenous prostaglandins and the initiation of labor. Acta Obstet. Gynecol. Scand. 37(Suppl): 7-16.

12. Chapo, A. I. 1977. Inhibition of prostaglandin synthesis and contractility in the rabbit and rat uterus by ibuprofen. Prostaglandins. 13: 735-743.

13. Dusting, G. J., S. Moncada, and J. R. Vane. 1978. Disappearance of prostacyclin $\left(\mathrm{PGI}_{2}\right)$ in the circulation of the dog. Br. J. Pharmacol. 62: 414P-415P.
14. Gryglewski, R. J., R. Korbut, and A. Ocetkiewicz. 1978. Generation of prostacyclin by lungs in vivo and its release into the arterial circulation.Nature (Lond.). 273: 765-767.

15. Shebuski, R. J., and Aiken, J. W. 1980. Angiotensin II induced renal prostacyclin release suppresses platelet aggregation in the anesthetized dog. Adv. Prostaglandin Thromboxane Res. 7: 1148-1152.

16. Brown, J. J., D. L. Davies, P. B. Doak, A. F. Leven, and J. I. J. Robertson. 1966. Serial estimation of plasma renin concentration during pregnancy and after parturition. $J$. Endocrinol. 35: 373-378.

17. Bartter, F. C., J. R. Gill, Jr., J. C. Frölich, R. E. Bowden, J. W. Hollifield, N. Radfar, H. R. Keiser, J. A. Oates, H. Seyberth, and A. A. Taylor. 1976. Prostaglandins are overproduced by the kidneys and mediate hyperreninemia in Bartter's syndrome. Trans. Assoc. Amer. Phys. 89: 77-91.

18. Terragno, N. A., D. A. Terragno, and J. C. McGiff. 1977. Contribution of prostaglandins to the renal circulation in conscious, anesthetized, and laparotomized dogs. Circ. Res. 40: 590-595. 